\title{
Evaluation of Fruit Fly (Diptera: Tephritidae) Monitoring Systems on Mango in Limpopo Province, South Africa
}

\author{
Elsje Joubert ${ }^{1}$, Tertia Grové ${ }^{2}$ and Gerhard Booysen ${ }^{3}$ \\ 1. South African Subtropical Growers' Association, Tzaneen 0850, South Africa \\ 2. Agricultural Research Council, Tropical and Subtropical Crops, Nelspruit 1200, South Africa \\ 3. Insect Science (Pty) Ltd., Tzaneen 0850, South Africa
}

\begin{abstract}
Fruit fly species' responses to lures are critically important, especially when a single lure might be recommended for the purpose of trapping multiple fruit fly species in commercial fruit orchards. Fruit industries are facing threats from the recent invasion of the oriental fruit fly Bactrocera dorsalis (Hendel) into novel areas in South Africa. The objective of this study was to test the relative efficiency of 13 different trapping systems for fruit fly species in mango orchards in South Africa. Evaluation of the different monitoring systems was conducted during the 2013-2014 mango season in the Vhembe district municipality of Limpopo, South Africa. Four orchards, where Tommy Atkins was cultivated, were used to compare the efficacy of the trapping systems. Trapping data $(N=48$ observation incidences per trapping system) were analyzed using a non-parametric ANOVA. Pronounced variation in species attractiveness across the trapping systems was found. The enriched ginger oil (EGO) Pherolure ${ }^{\mathrm{TM}}$ captured $33.77 \%$ of all the Ceratitis spp., while the Invader-lure ${ }^{\mathrm{TM}}$ captured $36.47 \%$ of the total number of $B$. dorsalis trapped. Torula yeast pellets are not recommended for fruit fly trapping due to the relative low trap catch numbers and high non-target catches. These results are important and significant for on-farm monitoring strategies, as well as for invasion monitoring systems currently in place to detect the distribution of B. dorsalis in South Africa.
\end{abstract}

Key words: Fruit fly lure, Diptera, Tephritidae monitoring systems, mango.

\section{Introduction}

In Africa, there are approximately 1,000 known fruit fly species (Diptera: Tephritidae), which belong to 150 genera [1], of which 50 species are of economic importance. Fruit fly species of economic importance are also associated with mango production in Africa [2-8]. In South Africa, three Ceratitis species pose a significant threat to fruit industries, namely, the Marula fruit fly-Ceratitis (Ceratalaspis) cosyra (Walker), which is especially significant in terms of mango production and is usually the most abundant species in mango orchards; the Natal fruit fly-Ceratitis (Pterandrus) rosa (Karsch); and the Mediterranean fruit fly-Ceratitis (Ceratitis) capitata (Wiedemann) [9, 10]. The oriental fruit

Corresponding author: Elsje Joubert, Ph.D., research fields: integrated pest management, insect physiology, applied entomology and best agricultural management practices.
fly_Bactrocera dorsalis (Hendel) was detected in Africa for the first time in Kenya in 2003; it initially was described as $B$. invadens Drew, Tsuruta and White and now synonymised with $B$. dorsalis $[2,11]$. Since the arrival of $B$. dorsalis in Africa, it has rapidly spread throughout the African continent into many newly-invaded fruit-producing countries [5, 12]. $B$. dorsalis was detected in South Africa for the first time in 2010 [13]. It was declared to be present in Vhembe district municipality in northern parts of the country during 2013 [14]. It has since spread rapidly throughout the northern part of the country, where mango is cultivated commercially.

The first step for the successful management of fruit flies in fruit orchards is to have an effective monitoring system. Monitoring is important to: (1) identify species present in the orchard to establish whether there is in fact a pest problem, (2) determine 
seasonal changes in population levels, (3) give an indication of the population present and the severity of pest, (4) determine the time for control actions to be initiated and (5) determine the efficacy of control measures.

Two main types of attractants can be used in the monitoring of fruit fly species, i.e., male lures and food baits. Male lures are mostly parapheromones that are highly species-specific, and they are effective in attracting fruit flies from long distances $[15,16]$. Methyl eugenol is a male attractant used for monitoring male Bactrocera species and is used in South Africa for the surveillance of B. dorsalis [17, 18]. Methyl eugenol can be chemically described as 4-allyl-1,2-dimethoxybenzene [17]. Studies on $B$. dorsalis have demonstrated that ingestion of methyl eugenol increases male mating success [19]. Enriched ginger oil (EGO) is a source of alpha-coapane and is known to be an attractant for Ceratitis species $[6,20$, 21]. It also has a male enhancing component, because exposure to its aroma increases the mating success of males [22-24]. C. cosyra was especially strongly attracted to EGO in a study conducted in mango orchards in South Africa [6].

Attraction of both sexes of $B$. dorsalis to three-component lure, a food bait that consists of ammoniumacetate, trimethylamine hydrochloride and putrescine, had also been reported and is also used in the surveillance of B. dorsalis in South Africa [18]. Both males and females of $C$. capitata, $C$. cosyra and C. rosa respond to three-component lure [6]. The second food bait, Torula yeast, is an autolysed yeast protein and attracts males and females of different fruit fly species [25].

The general objective of this study was to evaluate the efficacy of different lures and traps (trapping systems) for monitoring the complex of fruit flies associated with mango production in the Limpopo province of South Africa, with the specific objective to identify the best monitoring system to detect Ceratitis species and $B$. dorsalis presence in commercial mango orchards and to assess the extent to which non-target species were trapped in the systems.

\section{Materials and Methods}

\subsection{Study Site}

Evaluation of the different monitoring systems was conducted during 2014 in the Vhembe district of the Limpopo province in South Africa. Evaluation was done in four mango orchards of the Tommy Atkins cultivar. The site coordinates at $23^{\circ} 06^{\prime} 32^{\prime \prime} \mathrm{S}$ and $30^{\circ} 16^{\prime} 33^{\prime \prime}$ E. The orchards were 10-12 years old and under dry land cultivation. No pesticides were used in these orchards during the trial.

\subsection{Tephritidae Monitoring Systems}

Thirteen different monitoring systems were evaluated and compared. A brief description of each lure (including supplier details) and the trap used in the system is given in Table 1. Three different types of traps were used (Table 1).

The McPhail trap consisted of three parts, i.e. a yellow bottom section, shaped as an inverted funnel, a transparent top and a plastic water ring. The transparent top houses a plastic basket for lures. The height of the trap is $190 \mathrm{~mm}$ and the width is $175 \mathrm{~mm}$.

The Chempac yellow bucket trap consisted of a yellow bucket with a transparent lid. Apart from the funnel on the base of the bucket, it has three side holes, through which some transparent cylindrical tubes are introduced towards the inside. The height of the trap is $160 \mathrm{~mm}$ and the width is $135 \mathrm{~mm}$.

The Lynfield trap used consisted of yellow bucket and lid. The bucket had with four holes at the side and 12 small holes in the bottom of the trap. The height of the trap is $120 \mathrm{~mm}$ and the width $130 \mathrm{~mm}$.

\subsection{Trapping Methods}

To evaluate the efficacy of the monitoring systems, traps were placed $1.5 \mathrm{~m}$ above the ground on the southern side of a mango tree in four mango orchards 


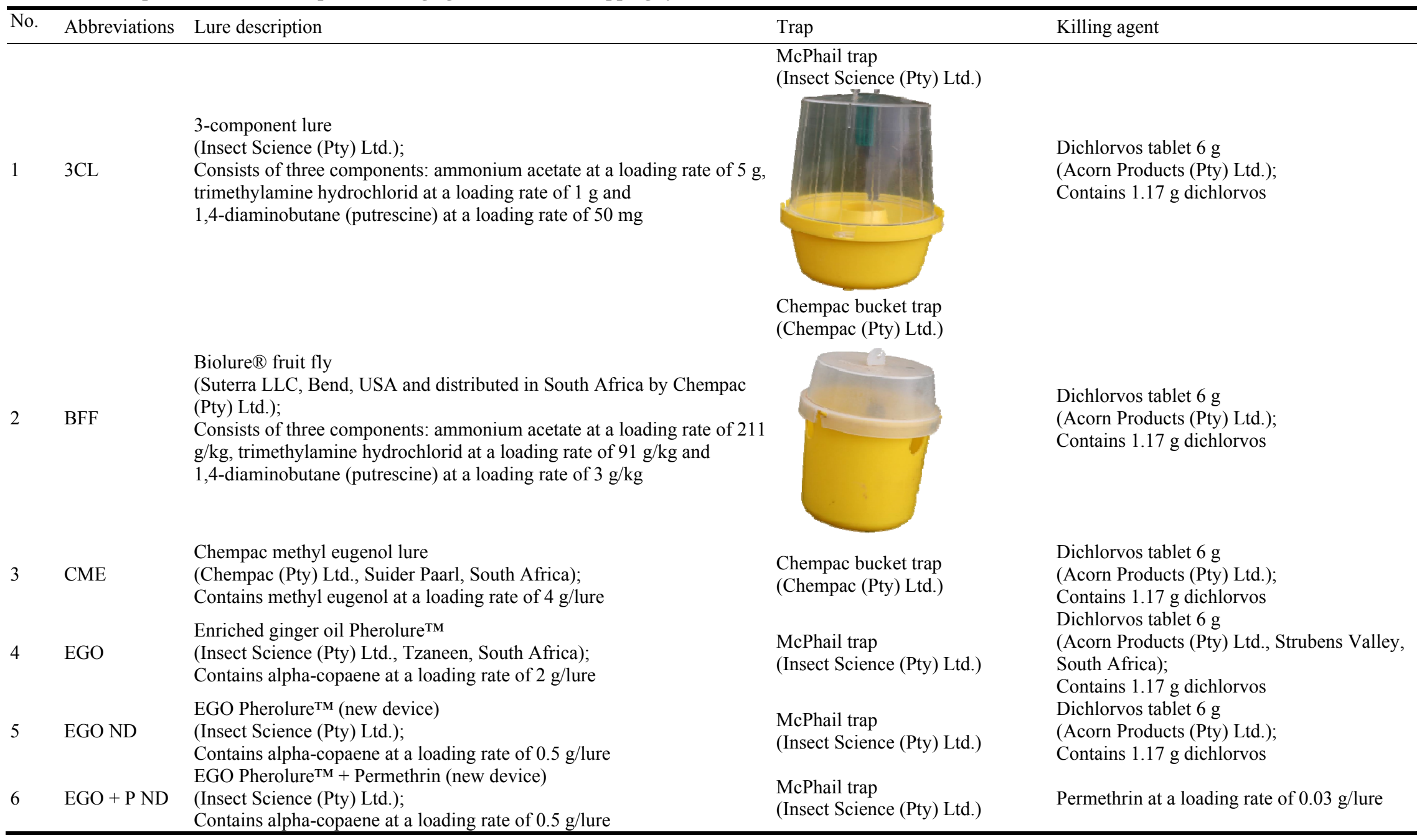




\begin{tabular}{|c|c|c|c|c|}
\hline No. & Abbreviations & Lure description & Trap & Killing agent \\
\hline 7 & IL & $\begin{array}{l}\text { Invader-lure } \\
\text { (River BioScience (Pty) Ltd., Addo, South Africa); } \\
\text { Contains methyl eugenol at a loading rate of } 15 \mathrm{~g} / \mathrm{block}\end{array}$ & $\begin{array}{l}\text { Lynfield trap } \\
\text { (River BioScience (Pty) Ltd.) }\end{array}$ & $\begin{array}{l}\text { Dichlorvos tablet } 6 \mathrm{~g} \\
\text { (Acorn Products (Pty) Ltd.); } \\
\text { Contains } 1.17 \mathrm{~g} \text { dichlorvos }\end{array}$ \\
\hline 8 & ME & $\begin{array}{l}\text { Methyl eugenol Pherolure } \\
\text { (Insect Science (Pty) Ltd.); } \\
\text { Contains methyl eugenol at a loading rate of } 2 \mathrm{~g} / \text { lure }\end{array}$ & $\begin{array}{l}\text { McPhail trap } \\
\text { (Insect Science (Pty) Ltd.) }\end{array}$ & $\begin{array}{l}\text { Dichlorvos tablet } 6 \mathrm{~g} \\
\text { (Acorn Products (Pty) Ltd.); } \\
\text { Contains } 1.17 \text { g dichlorvos }\end{array}$ \\
\hline 9 & $\begin{array}{l}\mathrm{ME}+\mathrm{EGO} \\
\mathrm{ND}\end{array}$ & $\begin{array}{l}\mathrm{ME}+\mathrm{EGO} \text { Pherolure } \mathrm{TM} \text { (new device) } \\
\text { (Insect Science (Pty) Ltd.); } \\
\text { Contains methyl eugenol at a loading rate of } 0.5 \mathrm{~g} \text { and alpha-copaene of } \\
0.5 \mathrm{~g} / \text { lure }\end{array}$ & $\begin{array}{l}\text { McPhail trap } \\
\text { (Insect Science (Pty) Ltd.) }\end{array}$ & $\begin{array}{l}\text { Dichlorvos tablet } 6 \mathrm{~g} \\
\text { (Acorn Products (Pty) Ltd.); } \\
\text { Contains } 1.17 \mathrm{~g} \text { dichlorvos }\end{array}$ \\
\hline 10 & $\begin{array}{l}\mathrm{ME}+\mathrm{EGO}+ \\
\text { P ND }\end{array}$ & $\begin{array}{l}\mathrm{ME}+\mathrm{EGO} \text { Pherolure } \mathrm{TM}+\text { Permethrin (new device) } \\
\text { (Insect Science (Pty) Ltd.); } \\
\text { Contains methyl eugenol at a loading rate of } 0.5 \mathrm{~g} \text { and alpha-copaene of }( \\
0.5 \mathrm{~g} / \text { lure }\end{array}$ & $\begin{array}{l}\text { McPhail trap } \\
\text { (Insect Science (Pty) Ltd.) }\end{array}$ & Permethrin at a loading rate of $0.06 \mathrm{~g} / \mathrm{lure}$ \\
\hline 11 & ME ND & $\begin{array}{l}\text { ME Pherolure }{ }^{\mathrm{TM}} \text { (new device) } \\
\text { (Insect Science (Pty) Ltd.); } \\
\text { Contains methyl eugenol at a loading rate of } 1 \mathrm{~g} / \text { lure }\end{array}$ & $\begin{array}{l}\text { McPhail trap } \\
\text { (Insect Science (Pty) Ltd.) }\end{array}$ & $\begin{array}{l}\text { Dichlorvos tablet } 6 \mathrm{~g} \\
\text { (Acorn Products (Pty) Ltd.); } \\
\text { Contains } 1.17 \text { g dichlorvos }\end{array}$ \\
\hline 12 & $\mathrm{ME}+\mathrm{P} \mathrm{ND}$ & $\begin{array}{l}\text { ME Pherolure }{ }^{\mathrm{TM}}+\text { Permethrin (new device) } \\
\text { (Insect Science (Pty) Ltd.) } \\
\text { Contains methyl eugenol at a loading rate of } 1 \mathrm{~g} / \text { lure }\end{array}$ & $\begin{array}{l}\text { McPhail trap } \\
\text { (Insect Science (Pty) Ltd.) }\end{array}$ & Permethrin at a loading rate of $0.06 \mathrm{~g} /$ lure \\
\hline 13 & TYP & $\begin{array}{l}\text { Torula yeast pellets (ISCA Technologies, Inc., California, USA); } \\
\text { One pellet was dissolved in } 500 \mathrm{~mL} \text { water }\end{array}$ & $\begin{array}{l}\text { Chempac bucket trap } \\
\text { (Chempac (Pty) Ltd.) }\end{array}$ & None, insects drown in the water mixture \\
\hline
\end{tabular}


in a complete randomized block design, following the method described by Leblanc et al. [25]. Trapping systems ( $\geq 30 \mathrm{~m}$ apart) were randomized weekly for six consecutive weeks (November-December, 2013). All the lures and DDVP (dichlorvos) containing tablets were replaced after completion and the trial continued for another six weeks with fresh lures (January-February 2014), randomising the traps weekly as before. Each treatment was replicated four times to result in a total of $N=48$ observations per trapping system. The fruit flies and non-target by-catch counts were taken weekly from each trap. Ceratitis spp. and $B$. dorsalis were identified. Morphological keys were used for identification of species [17, 26-28]. The sex of each fruit fly specimen was recorded. No-target insects were identified to order level and spiders to class level.

\subsection{Statistical Analysis}

Weekly randomization accounted for the effect of system location in the orchard on population density. The data (average weekly trap catches) for the final 6-week trial were analyzed using generalized linear models in $\mathrm{R}$ [29]. The assumption of homoscedasticity was tested for every statistical test to make sure the model was valid and the variance of the data means was equal (residual deviance $<$ degrees of freedom for the model). The mean model estimates were plotted and no overlap in $95 \%$ confidence intervals of the mean weekly trap catch data defined statistically heterogeneous treatment groups.

\section{Results}

Five fruit fly species were captured and identified during this study, namely, C. capitata, C. cosyra, $C$. rosa, $C$. quinaria (Bezzi) and $B$. dorsalis in addition to Perilampsis spp. (Fig. 1). The total number of fruit fly species captured with the percentage of the total number per species is given in Table 2 .

As shown in Fig. 1, the most abundant species captured were $C$. cosyra, followed by $C$. rosa and $C$. capitata. Low numbers of $C$. quinaria were present. A small number of fruit flies of the genus Perilampsis Bezzi were found in traps. Perilampsis is a small Afrotropical genus, not considered of economic importance, with hosts in the Loranthaceae family [30]. The highest percentage of $C$. cosyra (40.67\%), $C$. capitata $(34.56 \%)$ and C. rosa (34.73\%) responded to EGO Pherolure, which had the highest concentration of $\alpha$-copaene. EGO Pherolure captured $30.77 \%$ of the total number of fruit flies captured in the study. $C$. quinaria responded to EGO-containing products, but

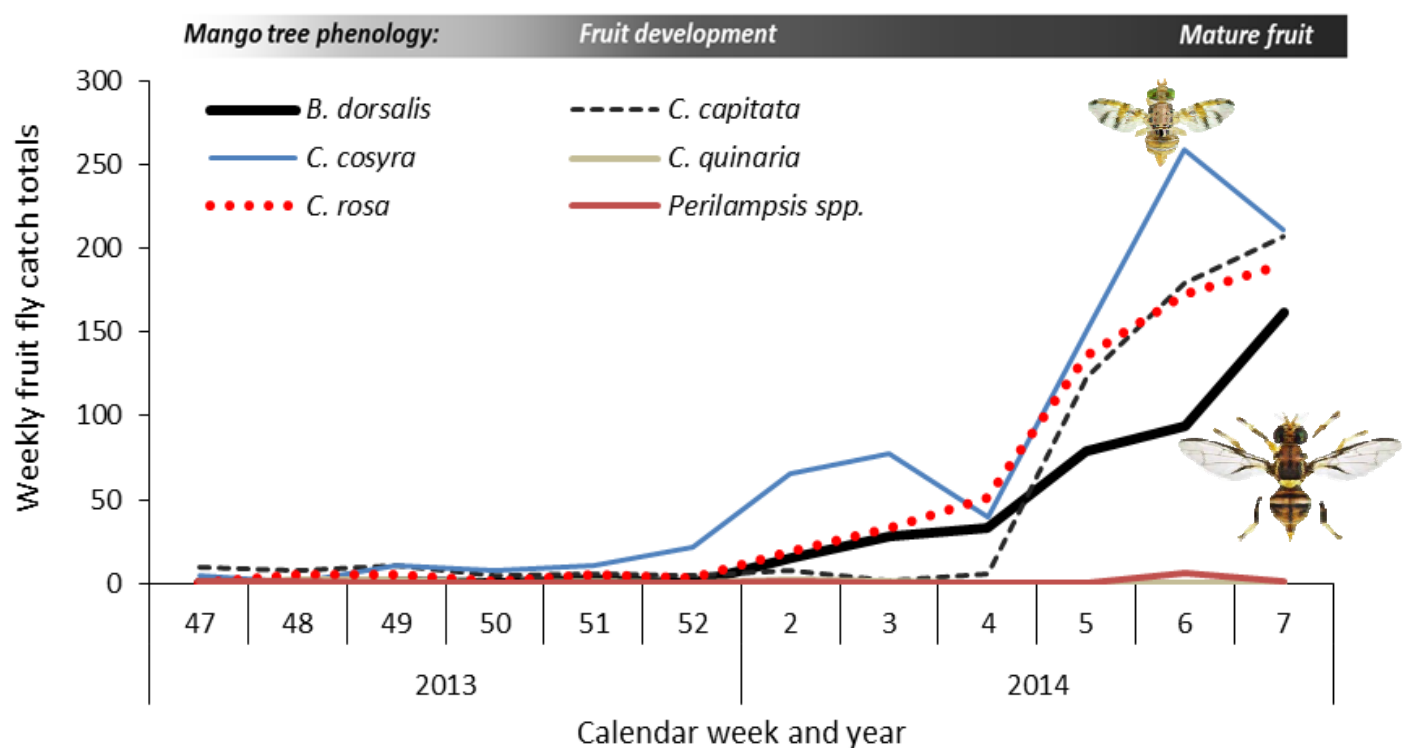

Fig. 1 Number of fruit flies per week across all 13 monitoring systems for the duration of 12 weeks. 
Table 2 Total number of fruit fly captured over a period of 12 weeks.

\begin{tabular}{|c|c|c|c|c|c|c|c|}
\hline \multirow{2}{*}{ Trapping system } & \multicolumn{7}{|c|}{ Total number of fruit fly captured } \\
\hline & C. capitata & C. cosyra & C. rosa & C. quinaria & B. dorsalis & Perilampsis spp. & Total \\
\hline $3 \mathrm{CL}$ & $3(0.53 \%)$ & $5(0.58 \%)$ & $15(2.41 \%)$ & - & $3(0.72 \%)$ & - & $26(1.05 \%)$ \\
\hline $\mathrm{BFF}$ & $27(4.74 \%)$ & $27(3.13 \%)$ & $119(19.13 \%)$ & - & $8(1.93 \%)$ & - & $181(7.28 \%)$ \\
\hline CME & - & - & - & - & $98(23.67 \%)$ & $1(10.00 \%)$ & $99(3.98 \%)$ \\
\hline EGO & $197(34.56 \%)$ & $350(40.67 \%)$ & $216(34.73 \%)$ & $2(25.00 \%)$ & - & - & $765(30.77 \%)$ \\
\hline EGO ND & $148(25.96 \%)$ & $211(24.48 \%)$ & $96(15.43 \%)$ & $1(12.50 \%)$ & $9(2.17 \%)$ & - & $465(18.70 \%)$ \\
\hline P ND & $100(17.54 \%)$ & $101(11.02 \%)$ & $72(11.58 \%)$ & $2(25.00 \%)$ & $8(1.93 \%)$ & - & $283(11.38 \%)$ \\
\hline IL & - & - & - & - & $151(36.47 \%)$ & $8(80.00 \%)$ & $159(6.40 \%)$ \\
\hline ME & - & - & - & - & $51(12.32 \%)$ & & $51(2.05 \%)$ \\
\hline $\mathrm{ME}+\mathrm{EGO} \mathrm{ND}$ & $48(8.42 \%)$ & $67(7.77 \%)$ & $39(6.27 \%)$ & $2(25.00 \%)$ & $24(5.80 \%)$ & $1(10.00 \%)$ & $181(7.28 \%)$ \\
\hline $\mathrm{ME}+\mathrm{EGO}+\mathrm{P} \mathrm{ND}$ & $46(8.07 \%)$ & $95(11.02 \%)$ & $47(7.56 \%)$ & & $22(5.31 \%)$ & - & $210(8.45 \%)$ \\
\hline ME ND & - & - & - & $1(12.50 \%)$ & $22(5.31 \%)$ & - & $23(0.93 \%)$ \\
\hline $\mathrm{ME}+\mathrm{P} \mathrm{ND}$ & - & $2(0.23 \%)$ & $1(0.16 \%)$ & - & $12(2.90 \%)$ & - & $15(0.60 \%)$ \\
\hline TYP & $1(0.18 \%)$ & $4(0.46 \%)$ & $17(2.73 \%)$ & - & $6(1.45 \%)$ & - & $28(1.13 \%)$ \\
\hline Total & $570(100 \%)$ & $862(100 \%)$ & $622(100 \%)$ & $8(100 \%)$ & $414(100 \%)$ & $10(100 \%)$ & $2,486(100 \%)$ \\
\hline
\end{tabular}

All the traps were re-baited after six weeks; the values given in brackets are the percentage of the total catch data for the respective species; -: indicated zero trap catches.

Table 3 Total number of male fruit fly captured over a period of 12 weeks.

\begin{tabular}{|c|c|c|c|c|c|c|c|}
\hline \multirow{2}{*}{ Trapping system } & \multicolumn{7}{|c|}{ Total number of male fruit fly captured } \\
\hline & C. capitata & C. cosyra & C. rosa & C. quinaria & B. dorsalis & Perilampsis spp. & Total \\
\hline $3 \mathrm{CL}$ & - & $3(0.36 \%)$ & $6(1.15 \%)$ & - & $2(0.49 \%)$ & - & $11(0.47 \%)$ \\
\hline BFF & $11(2.00 \%)$ & $5(0.60 \%)$ & $41(7.87 \%)$ & - & $5(1.23 \%)$ & - & $62(2.67 \%)$ \\
\hline CME & - & - & - & - & $98(24.20 \%)$ & $1(10.00 \%)$ & $99(4.26 \%)$ \\
\hline EGO & $197(35.82 \%)$ & $349(41.90 \%)$ & $216(41.46 \%)$ & $2(33.33 \%)$ & - & - & $764(32.86 \%)$ \\
\hline EGO ND & $148(26.91 \%)$ & $211(25.33 \%)$ & $96(18.43 \%)$ & $1(16.67 \%)$ & $9(2.22 \%)$ & - & $465(20.00 \%)$ \\
\hline $\mathrm{EGO}+\mathrm{P} \mathrm{ND}$ & $100(18.18 \%)$ & $101(12.12 \%)$ & $72(13.82 \%)$ & $2(33.33 \%)$ & $8(1.98 \%)$ & - & $283(12.17)$ \\
\hline IL & - & - & - & - & $151(37.28 \%)$ & $8(80.00 \%)$ & $159(6.84 \%)$ \\
\hline ME & - & - & - & - & $51(12.59 \%)$ & - & $51(2.19 \%)$ \\
\hline $\mathrm{ME}+\mathrm{EGO} \mathrm{ND}$ & $48(8.73 \%)$ & $67(8.04 \%)$ & $38(7.29 \%)$ & - & $24(5.93 \%)$ & $1(10.00 \%)$ & $178(7.66 \%)$ \\
\hline $\mathrm{ME}+\mathrm{EGO}+\mathrm{P} \mathrm{ND}$ & $46(8.36 \%)$ & $94(11.28 \%)$ & $47(9.02 \%)$ & - & $22(5.43 \%)$ & - & $209(8.99 \%)$ \\
\hline ME ND & - & - & - & $1(33.33 \%)$ & $22(5.43 \%)$ & - & $23(0.99 \%)$ \\
\hline $\mathrm{ME}+\mathrm{P} \mathrm{ND}$ & - & $2(0.24 \%)$ & $1(0.19 \%)$ & - & $12(2.96 \%)$ & - & $15(0.65 \%)$ \\
\hline TYP & - & $1(0.12)$ & $4(0.77 \%)$ & - & $1(0.25 \%)$ & - & $6(0.26 \%)$ \\
\hline Total & $550(100 \%)$ & $833(100 \%)$ & $521(100 \%)$ & $6(100 \%)$ & $405(100 \%)$ & $10(100 \%)$ & $2,325(100 \%)$ \\
\hline
\end{tabular}

All the traps were re-baited after six weeks; the values given in brackets are the percentage of the total catch data for the respective species; -: indicated zero trap catches.

one specimen was captured in a trap with methyl eugenol. The highest percentage of $B$. dorsalis $(36.47 \%)$ responded to Invader-lure (Table 2$)$. A small percentage $(<3 \%)$ of $B$. dorsalis responded respectively to the EGO Pherolure (new device) and EGO Pherolure + Permethrin (new device). $C$ capitata, C. cosyra and $C$. rosa were more responsive to lures containing EGO opposed to the combination with methyl eugenol. The addition of permethrin to EGO Pherolure (new device) seemed to have a negative effect, i.e., less catches on the response of $C$. capitata, $C$. cosyra and C. rosa. The addition of permethrin to ME Pherolure + EGO Pherolure (new device) did not seem to have an effect on the response of $C$. capitata, C. cosyra, C. rosa or B. dorsalis. The addition of permethrin to ME Pherolure (new device) had a negative effect on the response of $B$. dorsalis. Trap catch data for males and females are given in Table 3 and Table 4, respectively, and showed in Fig. 2. The food baits, i.e., Biolure fruit fly, 3-component lure and 


\section{Evaluation of Fruit Fly (Diptera: Tephritidae) Monitoring Systems on Mango in Limpopo Province, South Africa}

Torula yeast pellets typically captured the highest percentage of female fruit flies. The highest percentage of $B$. dorsalis females $(62.50 \%)$ was captured with the Torula yeast pellets, while Biolure fruit fly captured the highest percentage female of $C$.
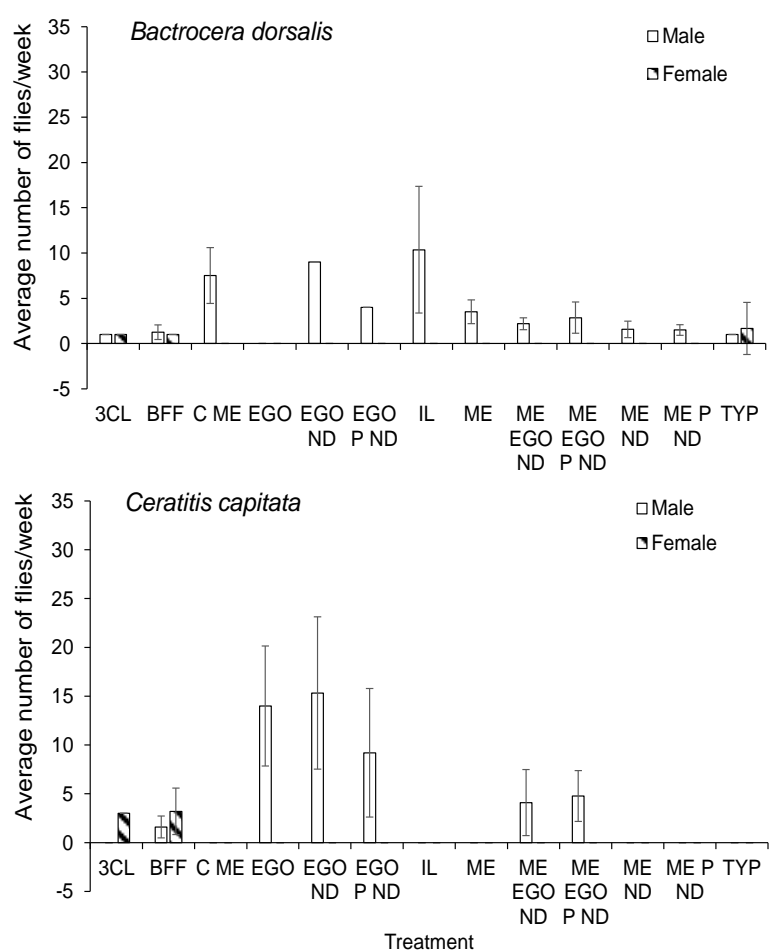

capitata, C. rosa and C. cosyra $(80.00 \%, 77.32 \%$ and $75.86 \%$, respectively) (Table 4).

Biolure fruit fly captured $73.91 \%$ of the total number of female flies (Table 4). Fig. 3 shows the results for the standard deviation of the average weekly
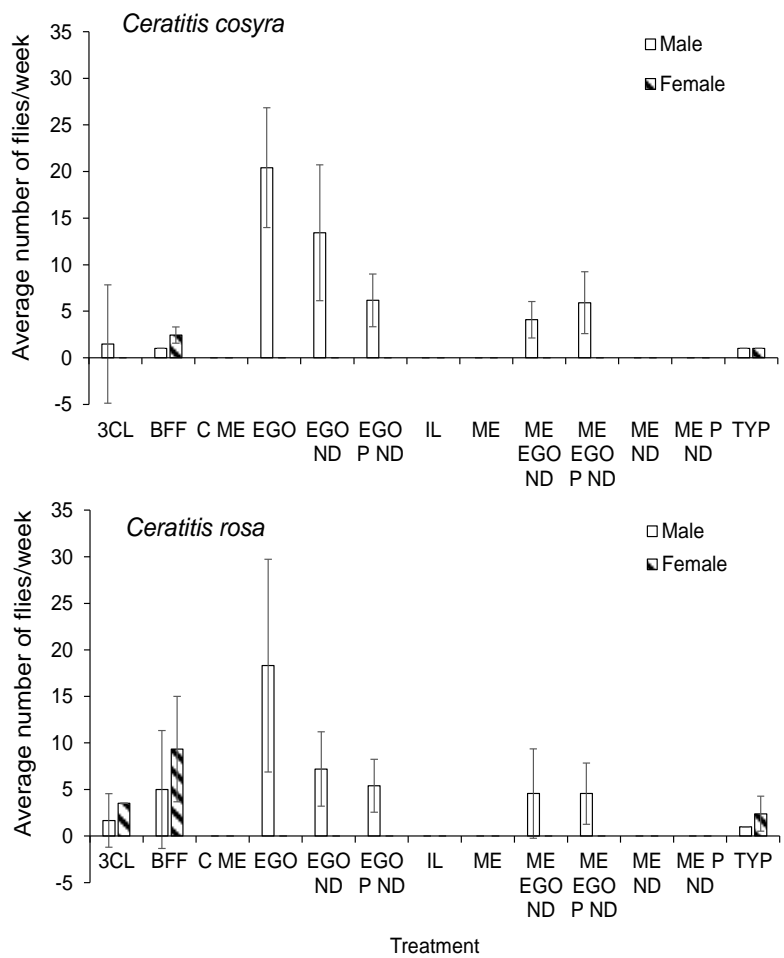

Fig. 2 Fruit fly catches (mean $\pm 95 \%$ confidence intervals) per species per week for 13 monitoring systems during calendar weeks 5-7, 2014 across four mango orchards.

Significant differences between treatments can be distinguished by no overlap in confidence intervals.

Table 4 Total number of female fruit fly captured over a period of 12 weeks.

\begin{tabular}{|c|c|c|c|c|c|c|c|}
\hline \multirow{2}{*}{ Trapping system } & \multicolumn{7}{|c|}{ Total number of female fruit fly captured } \\
\hline & C. capitata & C. cosyra & C. rosa & C. quinaria & B. dorsalis & Perilampsis spp. & Total \\
\hline $3 \mathrm{CL}$ & $3(15.00 \%)$ & $2(6.90 \%)$ & $9(8.91 \%)$ & - & $1(12.50 \%)$ & - & $15(9.32 \%)$ \\
\hline $\mathrm{BFF}$ & $16(80.00 \%)$ & $\begin{array}{l}22 \\
(75.86 \%)\end{array}$ & $78(77.23 \%)$ & - & $3(37.50 \%)$ & - & $119(73.91 \%)$ \\
\hline CME & - & - & - & - & - & - & - \\
\hline EGO & - & $1(3.45 \%)$ & - & - & - & - & $1(0.62 \%)$ \\
\hline EGO ND & - & - & - & - & - & - & - \\
\hline $\mathrm{EGO}+\mathrm{P} \mathrm{ND}$ & - & - & - & - & - & - & - \\
\hline IL & - & - & - & - & - & - & - \\
\hline ME & - & - & - & - & - & - & - \\
\hline $\mathrm{ME}+\mathrm{EGO} \mathrm{ND}$ & - & - & $1(0.99 \%)$ & $2(100 \%)$ & - & - & $3(1.86 \%)$ \\
\hline $\mathrm{ME}+\mathrm{EGO}+\mathrm{P} \mathrm{ND}$ & - & $1(3.45 \%)$ & - & - & - & - & $1(0.62 \%)$ \\
\hline ME ND & - & - & - & - & - & - & - \\
\hline $\mathrm{ME}+\mathrm{P}$ ND & - & - & - & - & - & - & - \\
\hline TYP & $1(5.00 \%)$ & $3(10.34 \%)$ & $13(12.87 \%)$ & & $5(62.50 \%)$ & - & $22(13.66 \%)$ \\
\hline Total & $20(100 \%)$ & $29(100 \%)$ & $101(100 \%)$ & $2(100 \%)$ & $9(100 \%)$ & & $161(100 \%)$ \\
\hline
\end{tabular}

All the traps were re-baited after six weeks; the values given in brackets are the percentage of the total catch data for the respective species; -: indicated zero trap catches. 
$B$. dorsalis trap catches (calculated over six weeks) with the average number of $B$. dorsalis caught per trap per week corrected for the loading rate of the methyl eugenol. The results showed that the new device containing $\mathrm{ME}+\mathrm{EGO}+$ Permethrin performed the best in terms of the corrected average value (Fig. 3).

There was a significant effect of trapping system on non-target catches $\left(\chi^{2}=236.09, \mathrm{df}=12, P<0.001\right)$. The numbers of non-target insects and Arachnida captured with the different monitoring systems over the total experimental period are given in Table 5. Of all the non-target species, Diptera was especially attracted to the different monitoring systems. The three food baits attracted the highest number of non-target

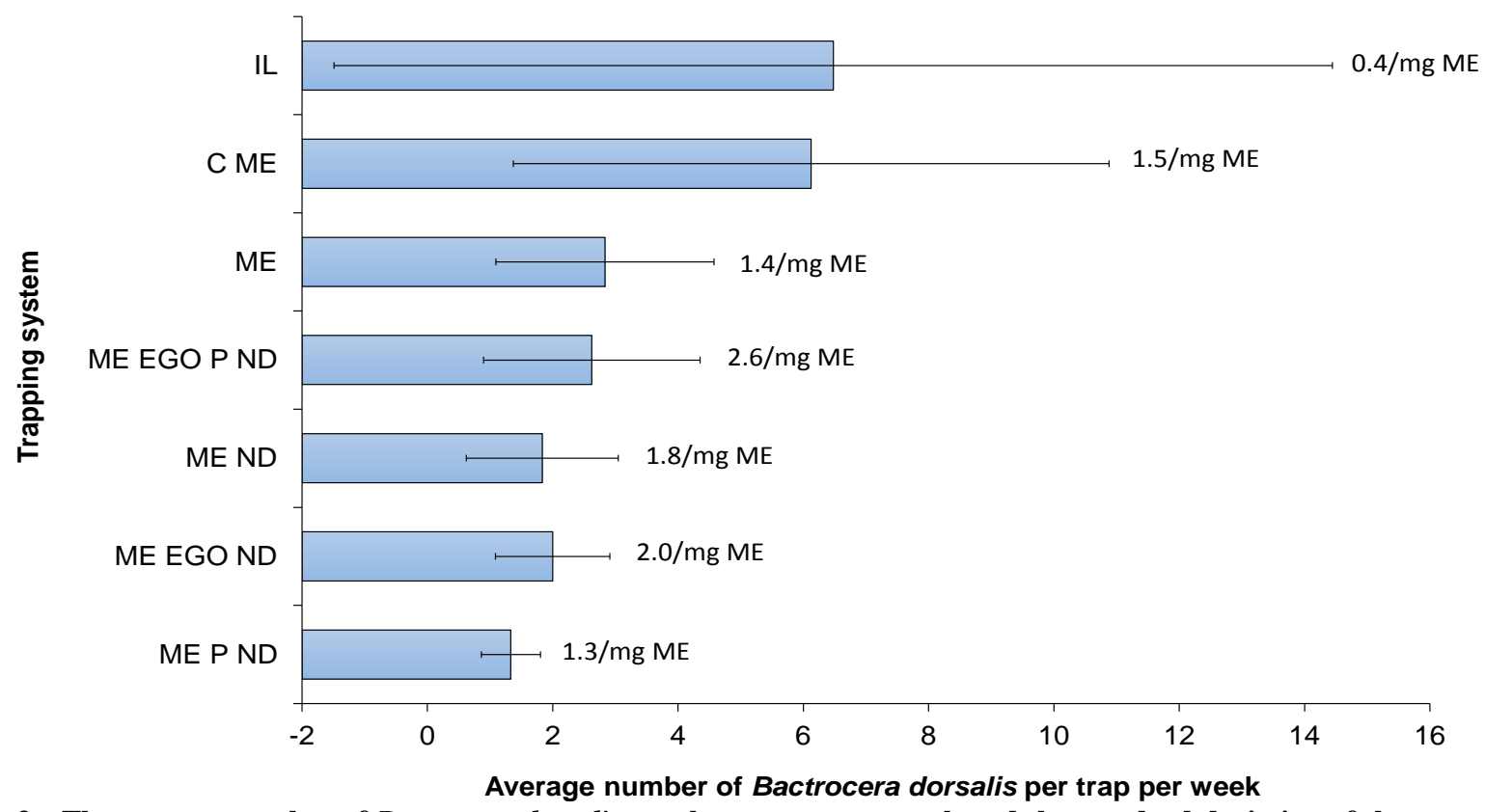

Fig. 3 The average number of Bactrocera dorsalis caught per trap per week and the standard deviation of the trap catches over the final six weeks of trapping.

The number of flies trapped per week per mg methyl eugenol is given next to the graph for every trapping system.

Table 5 Total number of non-target insect captured over a period of 12 weeks.

\begin{tabular}{llllll}
\hline \multirow{2}{*}{ Trapping system } & \multicolumn{5}{c}{ Total number of non-target insect captured } \\
\cline { 2 - 6 } & Diptera & Hymenoptera & Lepidoptera & Other & Total \\
\hline 3CL & $1,018(14.88 \%)$ & $135(10.45 \%)$ & $8(8.79 \%)$ & $20(5.15 \%)$ & $1,181(13.72 \%)$ \\
BFF & $1,291(18.87 \%)$ & $153(11.84 \%)$ & $8(8.79 \%)$ & $49(12.63 \%)$ & $1,501(17.43 \%)$ \\
CME & $458(6.7 \%)$ & $42(3.25 \%)$ & $0(0.00 \%)$ & $36(9.28 \%)$ & $536(6.22 \%)$ \\
EGO & $100(1.46 \%)$ & $52(4.02 \%)$ & $1(1.10 \%)$ & $22(5.67 \%)$ & $175(2.03 \%)$ \\
EGO ND & $97(1.42 \%)$ & $98(7.59 \%)$ & $0(0.00 \%)$ & $24(6.19 \%)$ & $219(2.54 \%)$ \\
EGO + P ND & $87(1.27 \%)$ & $79(6.11 \%)$ & $2(2.20 \%)$ & $32(8.25 \%)$ & $200(2.32 \%)$ \\
IL & $61(0.89 \%)$ & $13(1.01 \%)$ & $1(1.10 \%)$ & $15(3.87 \%)$ & $90(1.05 \%)$ \\
ME & $359(5.25 \%)$ & $99(7.66 \%)$ & $6(6.59 \%)$ & $26(6.7 \%)$ & $490(5.69 \%)$ \\
ME + EGO ND & $95(1.39 \%)$ & $37(2.86 \%)$ & $0(0.00 \%)$ & $30(7.73 \%)$ & $162(1.88 \%)$ \\
ME + EGO + P ND & $151(2.21 \%)$ & $66(5.11 \%)$ & $2(2.20 \%)$ & $25(6.44 \%)$ & $244(2.83 \%)$ \\
ME ND & $257(3.76 \%)$ & $58(4.49 \%)$ & $8(8.79 \%)$ & $34(8.76 \%)$ & $357(4.15 \%)$ \\
ME + P ND & $359(5.25 \%)$ & $52(4.02 \%)$ & $6(6.59 \%)$ & $37(9.54 \%)$ & $454(5.27 \%)$ \\
TYP & $2,507(36.65 \%)$ & $408(31.58 \%)$ & $49(53.85 \%)$ & $38(9.79 \%)$ & $3,002(34.86 \%)$ \\
\hline Total & $6,840(100 \%)$ & $1,292(100 \%)$ & $91(100 \%)$ & $388(100 \%)$ & $8,611(100 \%)$ \\
\hline AIf
\end{tabular}

All the traps were re-baited after six weeks; other non-target insect catches include the orders: Blattodea, Colleoptera, Hemiptera, Isoptera, Neuroptera, Orthoptera and Thysanoptera and the class Arachnida. 
Table 6 The non-parametric (generalized linear model with Poisson distribution of errors and log link function) statistics for the effects of monitoring system and species on the count data outcomes for calendar weeks 5-7.

\begin{tabular}{lllll}
\hline Sex of fruit flies & Parameter tested & $\chi^{2}$ & df & $P$ value \\
\hline \multirow{3}{*}{ Male } & Monitoring system & 155.42 & 12 & $<0.001$ \\
& Species & 450.65 & 4 & $<0.001$ \\
& Monitoring system $\times$ species & 126.81 & 19 & $<0.001$ \\
\hline \multirow{2}{*}{ Female } & Monitoring system & 5.29 & 2 & 0.071 \\
& Species & 12.40 & 3 & 0.006 \\
\hline
\end{tabular}

$\chi^{2}:$ the Chi-square value; df: degrees of freedom.

species and Torula yeast pellets attracted $34.86 \%$ of total non-target species captured. Invader-lure attracted the lowest number of non-target species, followed by ME Pherolure + EGO Pherolure (new device). The non-parametric statistics for the effects of monitoring system and species on the count data outcomes for calendar weeks 5-7 were summarized in Table 6 . There were significant differences for male fruit flies in the parameters monitoring system and species.

\section{Discussion}

Fruit fly numbers were low during the first six weeks of monitoring, and started to increase in the second six weeks of monitoring, i.e., calendar weeks 1-7 (Fig. 1). There was especially a rapid increase during calendar week 4 of 2014, and this rapid increase can be attributed to fruit maturity and the lack of orchard sanitation (Fig. 1). The invasive species, $B$. dorsalis was present and it is evident that this species is becoming more prominent in mango orchards in South Africa. The highest number of $B$. dorsalis males (151 males) was present in Invader-lure, followed by Chempac ME lure (98 males) and then ME Pherolure (51 males). The high capture rates with the Invader-lure system were probably due to the much higher concentration of methyl eugenol in this system (15 g vs. 1-4 g in the other methyl eugenol-containing systems). This monitoring system also attracted the least non-target species. ME Pherolure + EGO Pherolure (new device), ME Pherolure + EGO Pherolure + Permethrin (new device), ME Pherolure (new device) and ME Pherolure + Permethrin (new device) were lesser effective in capturing $B$. dorsalis males. Although EGO Pheroluredid not capture any $B$. dorsalis, EGO Pherolure (new device) and EGO Pherolure + Permethrin (new device) captured nine and eight $B$. dorsalis males, respectively. These findings are in accordance with Mwatawala et al. [21], who also reported a low response to enrich ginger oil-containing products.

EGO Pherolure was very effective in attracting males of C. capitata, C. cosyra and C. rosa. Only one C. cosyra female was captured in EGO Pherolure, indicating that it is a male lure. C. quinaria was also trapped in EGO-containing products. EGO Pherolure (new device) and EGO Pherolure + Permethrin (new device) were lesser effective in attraction of the Ceratitis spp., compared to EGO Pherolure which is probably due to a lower concentration of $\alpha$-copaene. ME Pherolure + EGO Pherolure (new device) and ME Pherolure + EGO Pherolure + Permethrin (new device) were not as effective as EGO Pherolure (new device) and EGO Pherolure + Permethrin (new device) in attracting Ceratitis spp.

\section{Conclusions}

The presence of $B$. dorsalis in fruit production areas of South Africa has serious implications for the fruit industries. It is therefore important to develop an effective management strategy for fruit flies in this country. Statistical analyses of the results showed a significant effect for the monitoring systems on different fruit fly species. The results suggested that however some trapping systems performed well, there was not a single trapping system adequate for trapping Ceratitis spp., and B. dorsalis simultaneously. The 
EGO Pherolure ${ }^{\mathrm{TM}}$ captured $33.77 \%$ of all the Ceratitis spp., while the Invader-lure ${ }^{\mathrm{TM}}$ captured $36.47 \%$ of all B. dorsalis catches. The food bait Biolure fruit fly attracted the highest number of female fruit flies. Torula yeast pellets attracted the highest number of $B$. dorsalis females and most non-target species. $B$. dorsalis females were rather trapped with 3-component lure, Biolure fruit fly and Torula yeast pellets, but only nine females were captured in total. This study clearly indicates that male lures are much more effective in attracting fruit fly species in comparison with food baits. Food baits attracted the highest number of female fruit flies. Food baits also attracted much higher numbers of non-target species. These results are important and significant for on-farm monitoring strategies as well as for invasion monitoring systems currently in place to detect the distribution of B. dorsalis in South Africa.

\section{Acknowledgments}

Financial and logistical support was provided by Insect Science (Pty) Ltd., Tzaneen, South Africa and the South African Mango Growers' Association. Great thanks go to Mr. Sandile Fungene, who kindly made the orchards available for the trials.

\section{References}

[1] De Meyer, M., Mohamed, S., and White, I. M. 2014. "Invasive Fruit Fly Pests in Africa: A Diagnostic Tool and Information Reference for the Four Asian Species of Fruit Fly (Diptera: Tephritidae) That Have Become Accidentally Established as Pests in Africa, Including the Indian Ocean Islands." Accessed February, 2014. http://www.africamuseum.be/fruitfly/AfroAsia.htm.

[2] Lux, S. A., Copeland, R. S., White, I. M., Manrakhan, A., and Billah, M. K. 2003. "A New Invasive Fruit Fly Species from the Bactrocera dorsalis (Hendel) Group Detected in East Africa." Insect Sci. Appl. 23 (4): 355-60.

[3] Lux, S. A., Ekesi, S., Dimbi, S., Mohamed, S., and Billah, M. 2003. "Mango-Infesting Fruit Flies in Africa: Perspectives and Limitations of Biological Approaches to Their Management." In Biological Control in IPM Systems in Africa. Wallingford, United Kingdom: Centre for Agriculture Bioscience International, 277-93.

[4] Rwomushana, I., Ekesi, S., Gordon, I., and Ogol, C. K. P.
O. 2008. "Host Plants and Host Plant Preference Studies for Bactrocera invadens (Diptera: Tephritidae) in Kenya, a New Invasive Fruit Fly Species in Africa." Ann. Entomol. Soc. Am. 101 (2): 331-40.

[5] Ekesi, S., Nderitu, P. W., and Rwomushana, I. 2006. "Field Infestation, Life History and Demographic Parameters of the Fruit Fly Bactrocera invadens (Diptera: Tephritidae) in Africa." Bull. Entomol. Res. 96 (4): 379-86.

[6] Grové, T., De Beer, M. S., and Joubert, P. H. 2009. "Monitoring Fruit Flies in Mango Orchards in South Africa and Determining the Time of Fruit Infestation." Acta Horticul. 820: 589-96.

[7] Vayssières, J. F., Korie, S., and Ayegnon, D. 2009. "Correlation of Fruit Fly (Diptera: Tephritidae) Infestation of Major Mango Cultivars in Borgou (Benin) with Abiotic and Biotic Factors and Assessment of Damage." Crop Prot. 28 (6): 477-88.

[8] Ambele, F. C., Billah, M. K., Afreh-Nuamah, K., and Obeng-Ofori, D. 2012. "Susceptibility of Four Mango Varieties to the Africa Invader Fly, Bactrocera invadens Drew, Tsuruta and White (Diptera: Tephritidae) in Ghana." J. Appl. Biosciences 49: 3425-34.

[9] Prinsloo, G. L., and Uys, V. M. 2015. Insects of Cultivated Plants and Natural Pastures in Southern Africa. Hatfield, South Africa: Entomological Society of Southern Africa.

[10] Grové, T. 2001. "Tephritidae." In Pests and Beneficial Arthropods of Tropical and Non-citrus Subtropical Crops in South Africa, edited by Van De Berg, M. A., De Villiers, E. A., and Joubert, P. H. Nelspruit, South Africa: ARC-Institute for Tropical and Subtropical Crops, 293-304.

[11] Schutze, M. K., Mahmood, K., Pavasovic, A., Bo, W., Newman, J., Clarke, A. R., Krosch, M. N., and Cameron, S. L. 2015. "One and the Same: Integrative Taxonomic Evidence That Bactrocera invadens (Diptera: Tephritidae) Is the Same Species as the Oriental Fruit Fly Bactrocera dorsalis." Syst. Entomol. 40 (2): 472-86.

[12] Mwatawala, M. W., De Meyer, M., Makundi, R. H., and Maerere, A. P. 2009. "An Overview of Bactrocera (Diptera: Tephritidae) Invasions and Their Speculated Dominancy over Native Fruit Fly Species in Tanzania." $J$. Entomol. 6 (1): 18-27.

[13] Manrakhan, A., Hattingh, V., Venter, J. H., and Holtzhauzen, M. 2011. "Eradication of Bactrocera invadens (Diptera: Tephritidae) in Limpopo Province, South Africa." Afr. Entomol. 19 (2): 650-9.

[14] International Plant Protection Convention (IPPC). 2013. "Pest Status of Bactrocera invadens in South Africa." Accessed December 10, 2013. https://www.ippc.int/en/ countries/south-africa/pestreports/2013/12/pest-status-ofbactrocera-invadens-in-south-africa-1/. 

Mango in Limpopo Province, South Africa

[15] Cunningham, R. T. 1989. "Parapheromones." In Fruit Flies: Their Biology, Natural Enemies and Control, edited by Robinson, A. S., and Hooper, G. Vol. 3A. Amsterdam: Elsevier, 221-8.

[16] White, I. M., and Elson-Harris, M. M. 1992. Fruit Flies of Economic Significance: Their Identification and Bionomics. Wallingford, UK: CAB International.

[17] White, I. M. 2006. Taxonomy of the Dacina (Diptera: Tephritidae) of African and the Middle East. Hatfield, South Africa: Entomological Society of Southern Africa.

[18] Manrakhan, A., Venter, J. H., and Hattingh, V. 2012. "Action Plan for the Control of the African Invader Fruit Fly, Bactrocera invadens Drew Tsuruta and White." Department of Agriculture, Forestry and Fisheries, Republic of South Africa, Pretoria. Accessed February, 2014. http://www.nda.agric.za/doaDev/sideMenu/plant Health/docs/Bactrocera\%20invadens\%20Action\%20Plan. pdf.

[19] Shelly, T. E., and Dewire, A. L. M. 1994. "Chemically Mediated Mating Success in Male Oriental Fruit Flies (Diptera: Tephritidae)." Ann. Entomol. Soc. Am. 87 (3): 375-82.

[20] Shelly, T. E., and Pahio, E. 2002. "Relative Attractiveness of Enriched Ginger Root Oil and Trimedlure to Male Mediterranean Fruit Flies (Diptera: Tephritidae)." Florida Entomol. 85 (4): 545-51.

[21] Mwatawala, M., Virgilio, M., Quilici, S., Dominic, M., and De Meyer, M. 2013. "Field Evaluation of the Relative Attractiveness of Enriched Ginger Root Oil (EGO) Lure and Trimedlure for African Ceratitis Species (Diptera: Tephritidae).” J. Appl. Entomol. 137 (5): 392-7.

[22] Shelly, T. E. 2001. "Exposure to $\alpha$-Copaene and
$\alpha$-Copaene Containing Oils Enhances Mating Success of Male Mediterranean Fruit Flies (Diptera: Tephritidae)." Ann. Entomol. Soc. Am. 94 (3): 497-502.

[23] Shelly, T. E., McInnis, D. O., Pahio, E., and Edu, J. 2004. "Aromatherapy in the Mediterranean Fruit Fly (Diptera: Tephritidae): Sterile Males Exposed to Ginger Root Oil in Pre-Release, Storage Boxes Display Increased Mating Competitiveness in Field-Cage Trials." J. Econ. Entomol. 97 (3): 846-53.

[24] Quilici, S., Schmitt, C., Vidal, J., Franck, A., and Deguine, J. P. 2013. "Adult Diet and Exposure to Semiochemicals Influence Male Mating Success in Ceratitis rosa (Diptera: Tephritidae)." J. Appl. Entomol. 137 (1): 142-53.

[25] Leblanc, L., Vargas, R. I., and Rubinoff, D. 2010. "Captures of Pest Fruit Flies (Diptera: Tephritidae) and Nontarget Insects in BioLure and Torula Yeast Traps in Hawaii.” Environ. Entomol. 39 (5): 1626-30.

[26] De Meyer, M. 1998. "Revision of the Subgenus Ceratitis (Ceratalaspis) Hancock (Diptera: Tephritidae)." Bull. Entomol. Res. 88 (3): 257-90.

[27] De Meyer, M. 2000. "Systematic Revision of the Subgenus Ceratitis MacLeay s.s. (Diptera: Tephritidae)." Zool. J. Linnean Soc. 128 (4): 439-67.

[28] De Meyer, M., and Freidberg, A. 2006. "Revision of the Subgenus Ceratitis (Pterandrus) Bezzi (Diptera: Tephritidae)." Israel J. Entomol. 35: 197-315.

[29] R Development Core Team. 2008. R: A Language and Environment for Statistical Computing. Ver. 3.1.0. Vienna, Austria: R Foundation for Statistical Computing.

[30] De Meyer, M. 2009. "Taxonomic Revision of the Fruit Fly Genus Perilampsis Bezzi (Diptera: Tephritidae).” Journal of Natural History 43 (39-40): 2425-63. 